\title{
Urinary albumin excretion in school children
}

\author{
A G DAVIES, R J POSTlethWAite, D A PRICE, J L BURN, C A HOUlTon, \\ AND B A FIELDING
}

Department of Child Health, University of Manchester, Royal Manchester Children's Hospital, Manchester and Bolton General Hospital, Bolton

SUMmARY Concentrations of albumin were measured by an enzyme linked immunoassay in 24 hour urine collections (divided into day and night-time samples) from 183 boys and 191 girls aged 4 to 16 years. The 24 hour albumin excretion rate and day and night-time albumin excretion rates all increased with age in both girls and boys. Albumin excretion during the day exceeded that at night in both girls and boys. Albumin excretion rates were higher in girls than boys during the day but there was no significant difference at night-time. The urinary albumin creatinine ratio showed no change with age, but was greater in girls than boys during the day and at night, and was also greater during the day than at night in both sexes. Graphs of normal values of albumin excretion rates and albumin creatinine ratios are provided.

Albumin excretion rates in diabetes mellitus have been studied extensively in adults ${ }^{12}$ and to a lesser extent in children. ${ }^{34}$ The starting point of any such study has to be the careful definition of normality using sufficiently sensitive methodology. As part of a study of renal function in diabetic children, an enzyme linked immunoassay (ELISA) technique for measuring albumin was developed, ${ }^{5}$ sensitive enough to measure the range of albumin found in normal urine.

In reported studies of albumin excretion in normal children, numbers have been too small to allow statistical analysis of age and sex differences, ${ }^{6}$ or the period of collection has been very limited. ${ }^{34}$ In the present study a large number of well motivated, normal school children were studied, 24 hour urine collections were split into timed night and daytime samples, collections likely to be incorrect ${ }^{7}$ were excluded, and albumin creatinine ratios $^{8}$ were compared with albumin excretion rates. The results are expressed in units corrected for surface area (to $1.73 \mathrm{~m}^{2}$ ) so that comparisons with the more extensive published reports on adults ${ }^{9-12}$ may be made.

\section{Subjects}

A total of 419 school children, not known to have renal disease, volunteered to collect urine over 24 hours. Collection consisted of a timed daytime sample (from after passing the first morning urine sample to the last sample before going to bed) and a timed night-time sample (from retiring to bed to the first morning sample the following day, 24 hours after the onset of the collection). After securing approval from the local ethical committee and the consent of the teaching staff at several schools, the informed consent of the parents and children was sought and received. Children were measured to within $1 \mathrm{~cm}$ and weighed to within $0.2 \mathrm{~kg}$ wearing light clothing and without shoes.

\section{Samples}

Two sample bottles (without preservative) were given to each child together with careful oral and written instructions to ensure accurate collections which were timed to the minute by parents or older children. The samples were returned via school immediately after completion of the night collection. Volumes were measured, timing noted, and $2 \mathrm{ml}$ aliquots were stored at $-20^{\circ} \mathrm{C}$ until analysis. Inactivated rabbit serum $(20 \mu \mathrm{l})$ was added to each sample to prevent adsorption of albumin to the sample tube.

Nineteen samples were rejected because of obvious inaccuracies, namely timing errors and enuresis. Twenty six (7\%) samples were rejected on the basis of creatinine excretion. ${ }^{7}$

\section{Methods}

Urine albumin concentration. The urine albumin 625

concentration was estimated by an ELISA 
technique, ${ }^{5}$ using commercially available reagents which had a sensitivity of $625 \mathrm{pg}$ per well, an intra-assay coefficient of variation of $4 \%$, and an inter-assay coefficient of variation of $9 \%$. Using this assay we were able to detect concentrations as low as $3 \mu \mathrm{g} / \mathrm{l}$ in urine.

Urine creatinine concentration. The urine creatinine concentration was measured using a semiautomated alkaline picrate method.

\section{Statistical methods}

The 24 hour albumin excretion, day and night-time albumin excretion rates, and albumin creatinine ratios were not normally distributed but showed positively skewed, thin peaked distributions. On logarithmic (base 10) transformation, these distributions became more Gaussian. Logarithmic transformation improved $\mathrm{g}_{1},{ }^{13}$ a measure of skew, from the range +0.01 to +0.02 on the raw data to the range $+1.6 \times 10^{-3}$ to $6.0 \times 10^{-3}$. Similarly $\mathrm{g}_{2},{ }^{13} \mathrm{a}$ measure of kurtosis, improved on logarithmic transformation from the range +4.82 to +15.58 on the raw data to -0.31 to +0.95 .

All further analyses were performed on transformed data and standard statistical methods ${ }^{14}$ were used. All tests of significance were two tailed. The results are expressed antilogged with a geometric mean (GM) equivalent to the arithmetic mean of the logged data, and a tolerance factor (TF) equivalent to the standard deviation of logged data, except that the GM is multiplied or divided by the TF. Normal ranges (Figs. 5 and 6 ) are given with the appropriate tolerance factors around each regression line.

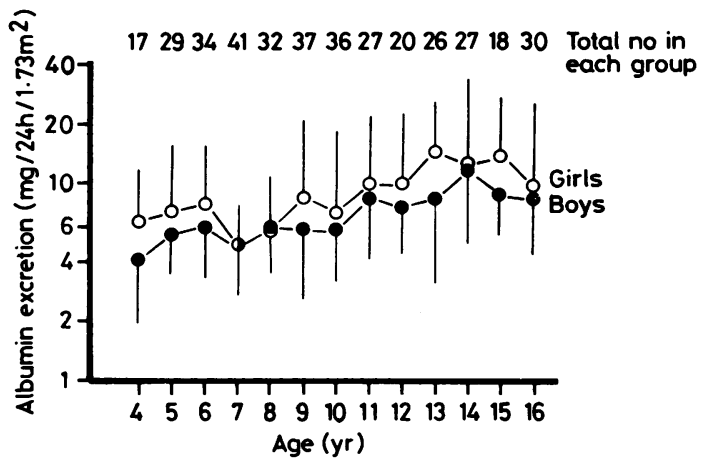

Fig. 1 Twenty four hour urinary albumin excretion rate. Geometric mean and tolerance factors are shown at each age for boys and girls aged from 4 to 16 years.
Table 1 Albumin excretion rate

\begin{tabular}{|c|c|c|c|}
\hline & $\begin{array}{l}\text { Geometric } \\
\text { mean } \\
\left(\mathrm{mg} / 24 \mathrm{~h} / 1.73 \mathrm{~m}^{2}\right)\end{array}$ & $\begin{array}{l}\text { Tolerance } \\
\text { factor }\end{array}$ & No \\
\hline & 6.64 & 1.98 & 183 \\
\hline \multirow[t]{2}{*}{ Girls } & $8 \cdot 30$ & $2 \cdot 21$ & 191 \\
\hline & \multicolumn{3}{|l|}{$\left(\mu \mathrm{g} / \min / 1.73 \mathrm{~m}^{2}\right)$} \\
\hline \multicolumn{4}{|c|}{ (1) } \\
\hline Day & $5 \cdot 64$ & 2.25 & 183 \\
\hline Night & 2.77 & 1.89 & 183 \\
\hline \multicolumn{4}{|l|}{ Girls } \\
\hline Day & 7.66 & $2 \cdot 43$ & 191 \\
\hline Night & 2.98 & 1.84 & 191 \\
\hline
\end{tabular}

\section{Results}

Urinary albumin excretion. The 24 hour albumin excretion in girls and boys is shown in Fig. 1 and Table 1. Albumin excretion in girls was significantly greater than in boys $(\mathrm{P}<0 \cdot 001)$ and the variance of values in girls was also significantly greater than the variance in boys $(\mathrm{P}<0 \cdot 05)$. There was a small but significant increase in the 24 hour albumin excretion rate related to age in both boys and girls between the ages studied ( 4 to 16 years) $(\mathrm{P}<0 \cdot 001)$.

Albumin excretion rate-daytime and night-time. Day and night-time excretion rates are shown in Figs. 2 and 3 and Table 1. The albumin excretion

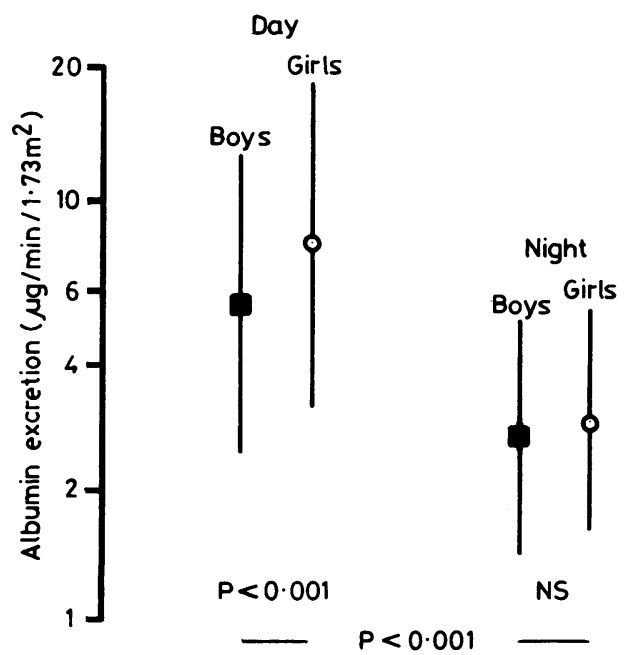

Fig. 2 Daytime and night-time urinary albumin excretion rates. Geometric mean and tolerance factors are shown for the total daytime and night-time collections of the entire study group. 


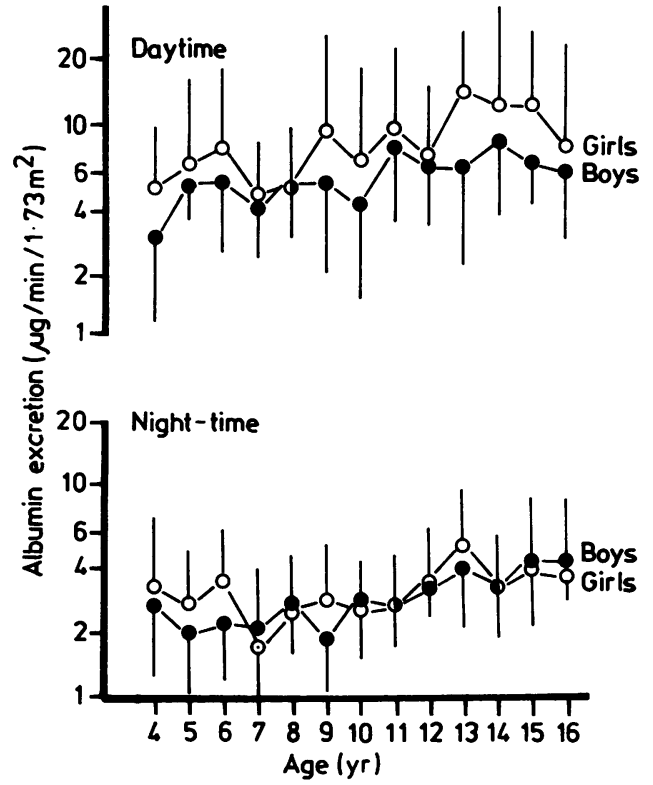

Fig. 3 Daytime and night-time urinary albumin excretion rates. Geometric mean and tolerance factor are shown at each age for boys and girls aged from 4 to 16 years.

rate in the daytime significantly exceeded the night-time rate $(\mathrm{P}<0 \cdot 001)$. In both girls and boys the geometric mean and variance of daytime albumin excretion significantly exceeded the geometric mean and variance of the night-time rate $(P<0.001)$. Although the daytime albumin excretion in girls was significantly greater than the daytime albumin excretion in boys $(P<0 \cdot 001)$, there was no significant

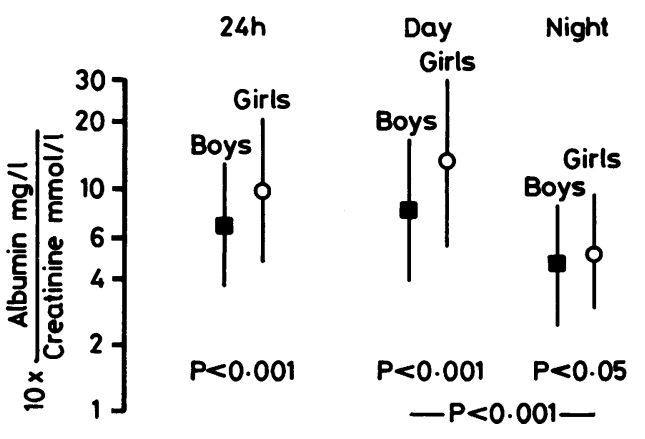

Fig. 4 Albumin creatinine ratios. Geometric mean and tolerance factors are shown for the 24 hour, day, and night-time urine collections of the entire study group.
Table 2 Albumin creatinine ratio $(10 \times($ albumin $(\mathrm{mg} / \mathrm{l}) \div$ creatinine $(\mathrm{mmol} / \mathrm{l}))$

\begin{tabular}{lclll}
\hline & $\begin{array}{l}\text { Geometric } \\
\text { mean }\end{array}$ & $\begin{array}{l}\text { Tolerance } \\
\text { factor }\end{array}$ & Range* & No \\
\hline Boys & 6.90 & 1.89 & 1.93 to 24.65 & 183 \\
Girls & 10.05 & 2.12 & 2.24 to 45.17 & 191 \\
Boys & & & & \\
$\quad$ Day & 8.08 & 2.09 & 1.85 to 35.29 & 183 \\
$\quad$ Night & 4.59 & 1.85 & 1.34 to 15.71 & 183 \\
Girls & 13.07 & 2.37 & 2.33 to 73.41 & 191 \\
$\quad$ Day & 5.24 & 1.81 & 1.60 to 17.17 & 191 \\
$\quad$ Night & & & & \\
\hline
\end{tabular}

Conversion factor-to obtain a ratio of $10 \times($ albumin $\mathrm{mg} / \mathrm{l} \div$ creatinine $\mathrm{mg} / \mathrm{l})$ divide by $113 \cdot 1$.

${ }^{*}$ Range $=$ geometric mean $\underset{\leftarrow}{\times}(\text { tolerance factor })^{2}$.

difference when night-time albumin excretion was considered. There was a significant positive correlation between daytime and night-time albumin excretion $(\mathrm{r}=0.42, \mathrm{P}<0.001)$. All albumin excretion rates-day and night, in boys and girls-showed a significant though small rise with age $(\mathrm{P}<0.02)$. There were no significant differences in urine flow rates between girls and boys, and flow rates (corrected to $1.73 \mathrm{~m}^{2}$ ) did not change significantly in relation to age.

Albumin creatinine ratio-daytime and night-time. Albumin creatinine ratios are given in Fig. 4 and Table 2. The daytime albumin creatinine ratio in girls significantly exceeded the night-time ratio $(P<0.001)$ and the variance of the daytime albumin creatinine ratio significantly exceeded the variance of the night-time ratio $(\mathrm{P}<0 \cdot 001)$. Similarly, in boys the geometric mean and variance of the daytime albumin creatinine ratio were both significantly greater than the geometric mean and variance of the night-time albumin creatinine ratio $(\mathrm{P}<0.001$ and $\mathrm{P}<0.02$ respectively).

Table 3 Relation between the albumin excretion rate $\left(\mu \mathrm{g} / \mathrm{min} / 1.73 \mathrm{~m}^{2}\right)$ and albumin creatinine ratio $(10 \times($ albumin $(\mathrm{mg} / \mathrm{l}) \div$ creatinine $(\mathrm{mmol} / \mathrm{l}))$

\begin{tabular}{llll}
\hline & No & $r$ & $P$ value \\
\hline Boys & & & \\
$\quad$ Day & 183 & 0.87 & $<0 \cdot 001$ \\
$\quad$ Night & 183 & $0 \cdot 77$ & $<0 \cdot 001$ \\
Girls & 191 & 0.91 & $<0 \cdot 001$ \\
$\quad$ Day & 191 & $0 \cdot 82$ & $<0 \cdot 001$ \\
Night & & 0.89 & $<0 \cdot 001$ \\
Total & 748 & 0.89 & \\
\hline
\end{tabular}




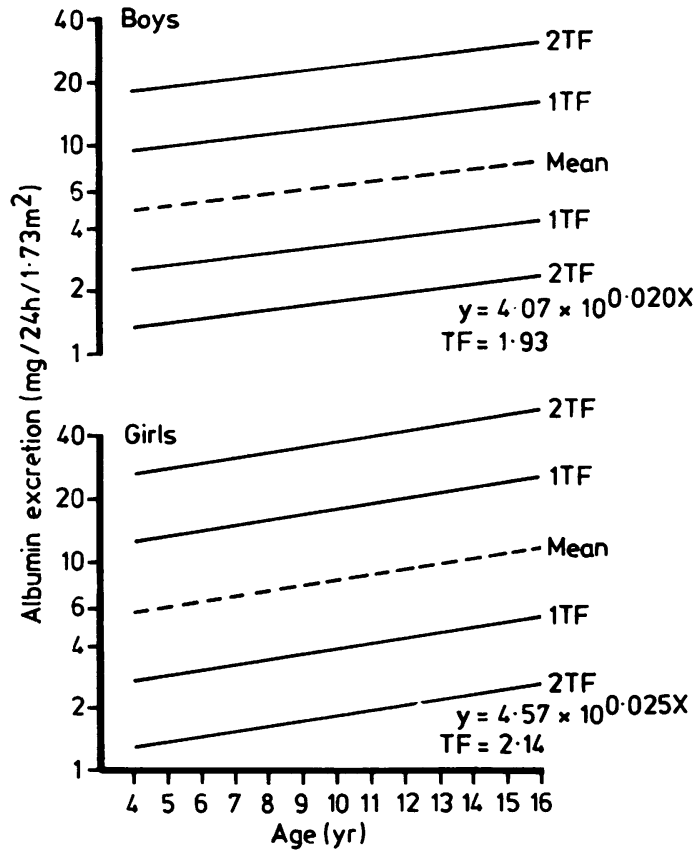

Fig. 5 Normal ranges of 24 hour urinary albumin excretion. The calculated regression lines are shown for 24 hour urine collections in normal boys and girls aged from 4 to 16 years.

$\mathbf{T F}=$ tolerance factor

The daytime albumin creatinine ratio in girls was significantly greater than in boys' $(\mathrm{P}<0.001)$ and at night-time the albumin creatinine ratio for girls was significantly greater than the boys $(P<0.05)$. The variance of the daytime ratio in girls was significantly greater than the variance of the daytime albumin creatinine ratio in boys $(\mathrm{P}<0.05)$ but there was no difference in the variance of the night-time ratio between boys and girls.

The albumin creatinine ratio showed no significant relation to age. Albumin creatinine ratios correlated well with albumin excretion rates (Table 3).

Normal ranges of albumin excretion rates and albumin creatinine ratios. Regression lines with appropriate tolerance factors are given in Figs. 5 and 6 for the albumin excretion rates in relation to age. Each geometric mean was multiplied or divided by the tolerance factor to give the equivalent of one standard deviation and was multiplied or divided by the square of the tolerance factor to give the equivalent of two standard deviations from the mean. Table 2 shows the normal range about the geometric mean of the albumin creatinine ratio obtained by multiplying or dividing by the square of the tolerance factor.
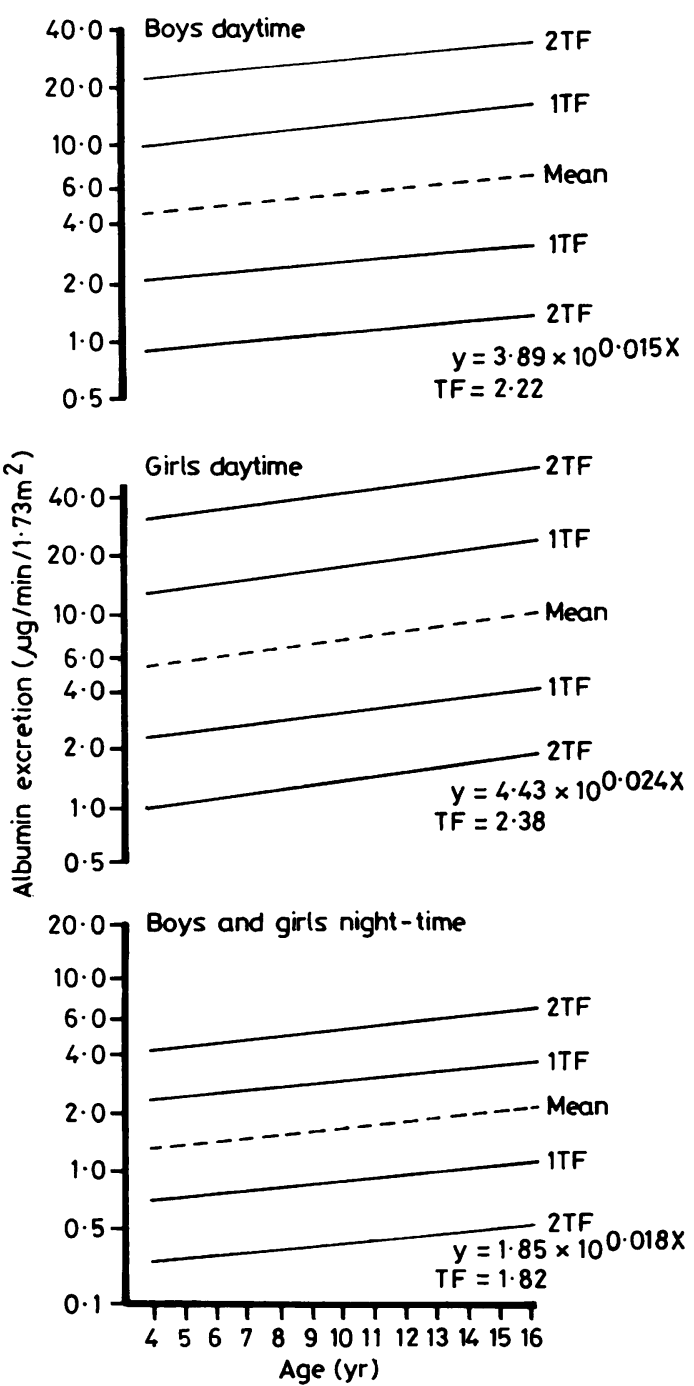

Fig. 6 Normal ranges of daytime and night-time urine albumin excretion. The calculated regression lines are shown for day and night-time urine collections in normal boys and girls aged from 4 to 16 years.

$\mathrm{TF}=$ tolerance factor 


\section{Discussion}

The ELISA method ${ }^{5}$ for measuring urinary albumin compares favourably in terms of sensitivity, selectivity, accuracy, and precision with radioimmunoassay ${ }^{11}{ }^{12}$ and immunonephelometry. ${ }^{6}$ Appreciable amounts of albumin were measured in all urine samples from normal children in this study. Logarithmic transformation of albumin excretion rates has been applied in relatively few studies ${ }^{1-4}$ but is essential in achieving normal distribution and facilitates statistical comparisons.

Comparisons with other studies of total daily albumin excretion are difficult - the geometric mean in this study was $6.6 \mathrm{mg} / 24 \mathrm{~h} / 1.73 \mathrm{~m}^{2}$ for boys and 8.3 $\mathrm{mg} / 24 \mathrm{~h} / 1.73 \mathrm{~m}^{2}$ for girls. Ellis and Buffone ${ }^{6}$ reported a mean of $5.5 \mathrm{mg} / 24 \mathrm{~h}$ in children but did not transform the data and did not correct for surface area. The results in our study, however, are similar to those reported for adults (if one assumes an average adult surface area of $1.73 \mathrm{~m}^{2}$ ). Berggård and Risinger ${ }^{9}$ reported a mean daily albumin excretion of $7.8 \mathrm{mg}$, Peterson et al ${ }^{10} 10.0 \mathrm{mg}$, and Miles et al ${ }^{11}$ $10 \cdot 1 \mathrm{mg}$.

There is no previous report to our knowledge of a significant sex difference in urinary albumin excretion, a very clear finding at all ages in this study. Hemmingsen and Skaarup ${ }^{15}$ failed to find any difference between males and females in 24 hour urine collections from 221 adults and 18 children, and Bohn, ${ }^{16}$ measuring albumin concentrations of overnight urine samples in 205 nephrologically normal subjects, found no significant sex difference. Either failure to correct for surface area obscured the sex difference in the two latter studies or no difference in urinary albumin excretion occurs in adults. It would be interesting to extend the present study beyond the ages of 4 to 16 years to answer this question. Because of differences in lean body mass ${ }^{17}$ one would expect the difference to be accentuated by relating albumin excretion to creatinine excretion, and indeed there was a significantly higher albumin creatinine ratio in girls, at night as well as during the day. But there was no difference between the boys' and girls' albumin excretion rate at night. There was no significant difference in flow rates between girls and boys to account for the higher albumin excretion rate in girls, and the difference was unlikely to be due to higher plasma concentrations of albumin in girls; indeed serum albumin is higher in boys than girls. ${ }^{18}$ (We considered it unethical and impractical to estimate plasma constituents at the onset of this study.) It is difficult to ascertain the amount of albumin added by contact of urine with the female perineum, but if this is negligible there may be a genuine difference between boys and girls in glomerular or tubular handling of albumin which requires further investigation.

The difference in albumin excretion rates during daytime and night-time has long been known, 1920 and it is likely that upright posture accounts for part of the increase in albumin excretion rates during the daytime. Increases in albumin excretion rates during minor exercise, for example running in play, probably contribute to the increase in daytime rates. It is noteworthy that the higher albumin excretion during daytime is seen when absolute excretion rates are calculated and also when related to creatinine excretion.

The small but significant age related increase in albumin excretion rates in boys and girls for both day and night has not been reported previously. There is no age relation when albumin creatinine ratios are calculated for this age range, presumably due to increasing lean body mass and creatinine excretion with age. In their key paper on the albumin creatinine ratio, Barratt et al ${ }^{8}$ showed a negative correlation with body size; the major contribution to the correlation being the high ratio in neonates attributed to increased permeability of the neonatal glomerulus. The magnitude of the age and sex effects on albumin excretion rates is small when compared with the difference between day and night-time. For example, daytime albumin excretion rates in girls are approximately $4 / 3$ of daytime albumin excretion rates in boys. Compare this with the $8 / 3$ difference in albumin excretion rates in girls beween day and night-time. The mean albumin excretion rate of 4 year old girls was approximately half that of 16 year old girls in the daytime. The choice of collection period, either daytime or night-time, is the most important factor determining albumin excretion.

The use of the albumin creatinine ratios as a measure of glomerular dysfunction was commended by Barratt et al ${ }^{8}$ for sound practical reasons, in that a random urine can be used, and precise timing of urine collection and blood sampling are unnecessary. There is a practical advantage in measuring the night-time albumin excretion rate rather than a 24 hour albumin excretion rate because collection is easier. The night-time excretion of albumin is lower and the variance is significantly smaller. This is of interest, but it is too early to give a value judgement on the relative merits of the daytime, night-time, and 24 hour albumin excretion rates and the albumin creatinine ratio as a sensitive indicator of early and minor renal changes such as those seen in diabetes mellitus. Furthermore, the 24 hour, daytime, and night-time albumin excretion rates and daytime and night-time albumin creatinine ratios 
must be compared with albumin excretion after provocative stimuli such as exercise. Our own early observations suggest there may be increasing variance in albumin excretion, dependent on the parameter measured, the lowest variance occurring at night-time and the highest occurring during exercise testing. It may be that a low variance is important when looking for reproducible but minor abnormalities of albumin excretion in a given individual.

Finally a plea must be made in seeking uniformity in the units used to express albumin excretion. We suggest that there should be correction for surface area (although the authors have no remit for $1.73 \mathrm{~m}^{2}$ rather than $1.0 \mathrm{~m}^{2}$ ). The best compromise at the moment seems to be the use of $\mu \mathrm{g} / \mathrm{min} / 1.73 \mathrm{~m}^{2}$ for short collection times such as exercise tests, or night-time collections, and $\mathrm{mg} / 24$ hour $/ 1.73 \mathrm{~m}^{2}$ for the measurement of 24 hour albumin excretion. It is hoped the normal ranges so expressed and contained in this study provide a useful basis for the further investigation of pathological conditions.

We thank the pupils and staff of Higher Lane County Primary, St Bernadette's R C Primary. Whitefield High. Bury Church and Manchester Grammar Schools for their cooperation; Dr G M Addison, Professor I B Houston, and J R Lane for technical support and advice; Drs A Gibbs and D B Gordon for statistical advice; and the Salford Department of Medical Illustration and Mrs $\mathrm{K}$ Cordwell for help in manuscript preparation.

Funding from the North West Regional Health Authority, The Wallness Children's Kidney Project and Marks and Spencer PLC. is gratefully acknowledged.

\section{References}

1 Parving HH, Oxenboll B, Svendsen PA et al. Early detection of patients at risk of developing diabetic nephropathy. A longitudinal study of urinary albumin excretion. Acta Endocrinol (Copenh) 1982:100:550-5.

2 Viberti GC, Jarrett RJ, Mahmud U, Hill RD, Argyropoulos A. Keen H. Microalbuminuria as a predictor of clinical nephropathy in insulin dependent diabetes mellitus. Lancet 1982:i: $143(1-2$.

Brochner-Mortenson J, Ditzel J, Mogensen CE, Rødbro P. Microvascular permeability to albumin and glomerular filtration rate in diabetic and normal children. Diabetologia 1979;16: $3(1) 7-11$.
${ }^{4}$ Huttunen NP, Käär M-L, Puukka R, Åkerblom HK. Exerciseinduced proteinuria in children and adolescents with Type 1 (insulin dependent) diabetes. Diabetologia 1981;21:495-7.

5 Fielding BA, Price DA, Houlton CA. Enzyme immunoassay for urinary albumin. Clin Chem 1983;29:355-7.

- Ellis D, Buffone GJ. New approach to evaluation of proteinuric states. Clin Chem 1977;23:660-70.

7 Ghazali S, Barratt TM. Urinary excretion of calcium and magnesium in children. Arch Dis Child 1974;49:97-101.

${ }^{8}$ Barratt TM, McLaine PN, Soothill JF. Albumin excretion as a measure of glomerular dysfunction in children. Arch Dis Child 1970;45:496-501.

9 Berggård I, Risinger C. Quantitative immunochemical determination of albumin in normal human urine. Acta Societatis Medicorum Upsaliensis 1961;66:217.

11 Peterson PA, Evrin P-E, Berggård I. Differentiation of glomerular, tubular, and normal proteinuria: determinations of urinary excretion of $\mathrm{B}_{2}$-microglobulin, albumin, and total protein. J Clin Invest 1969;48:1189-98.

1 Miles DW, Mogensen CE, Gundersen HJG. Radioimmunoassay for urinary albumin using a single antibody. Scand J Clin Lab Invest 1970;26:5-11.

12 Woo J, Floyd M, Cannon DC, Kahan B. Radioimmunoassay for urinary albumin. Clin Chem 1978;24:1464-7.

13 Shapiro SS, Wilk MB, Chen HJ. A comparative study of various tests for normality. Journal of the American Statisticians Association 1968;63:1343-72.

14 Armitage P. Statistical methods in medical research. London: Blackwell Scientific Publications, 1971.

15 Hemmingsen L, Skaarup P. The 24-hour excretion of plasma proteins in the urine of apparently healthy subjects. Scand J Clin Lab Invest 1975:35:347-53.

16 Bohn L. Evaluation of some qualitative and quantitative tests for proteinuria. Dan Med Bull 1973;20:25-9.

17 Forbes GB. Body and composition in adolescence. In: Falkner FT, Tanner JM, eds. Human growth-postnatal growth. vol 2. London: Baillier̀e Tindall, 1979:239-72.

${ }^{18}$ Lyngbye J, Krøll J. Quantitative immunoelectrophoresis of proteins in serum from a normal population: season-, age-, and sex-related variations. Clin Chem 1971;6:495-500.

${ }^{14}$ Robinson RR, Glenn WG. Fixed and reproducible orthostatic proteinuria. IV. Urinary albumin excretion by healthy human subjects in the recumbent and upright postures. J Lab Clin Med 1964:64:717-23.

${ }^{20}$ Montagna G, Buzio C, Calderini C, Quaretti P, Migone L. Relationship of proteinuria and albuminuria to posture and to urine collection period. Nephron 1983;35:143-4.

Correspondence to Dr A Davies, The Department of Child Health, Royal Manchester Children's Hospital, Pendlebury, Manchester M27 1HA.

Received 26 March 1984. 